\title{
Autoregulation of Root Nodule Formation: Signals of Both Symbiotic Partners Studied in a Split-Root System of Vicia sativa subsp. nigra
}

\author{
Anton A. N. van Brussel, Teun Tak, Kees J. M. Boot, and Jan W. Kijne \\ Leiden University, Institute of Molecular Plant Sciences, Wassenaarseweg 64, 2334 AL, Leiden, The Netherlands \\ Submitted 22 August 2001. Accepted 7 December 2001.
}

Inhibition of root nodule formation on leguminous plants by already induced or existing root nodules is called autoregulation of root nodule formation (AUT). Optimal conditions for AUT were determined using a split-root technique newly developed for Vicia sativa subsp. nigra. Infection of a root A with nodulating Rhizobium leguminosarum bv. viciae bacteria systemically inhibited nodulation of a spatially separated root $B$ inoculated 2 days later with the same bacteria. This treatment gives complete AUT (total absence of nodules on root B). Only partial AUT of root B was obtained by incubation of root $A$ with mitogenic nodulation (Nod) factors or with a noninfective strain producing normal mitogenic Nod factors. Nonmitogenic Nod factors did not evoke AUT. We identified two systemic plant signals induced by Rhizobium bacteria. Signal 1 (at weak buffering) was correlated with sink formation in $\operatorname{root} A$ and induced acidification of B-root medium. This signal is induced by treatment of root $A$ with (i) nodulating rhizobia, (ii) mitogenic Nod factors, (iii) nonmitogenic Nod factors, or (iv) the cytokinin zeatin. Signal 2 (at strong buffering) could only be evoked by treatment with nodulating rhizobia or with mitogenic Nod factors. Most probably, this signal represents the specific AUT signal. Induction of complete AUT appears to require actively dividing nodule cells in nodule primordia, nodule meristems, or both of root $A$.

Additional keywords: legume, supernodulation, vetch.

The root nodule bacterium Rhizobium leguminosarum induces formation of root nodules on common vetch (Vicia sativa subsp. nigra) and related leguminous plants. These root nodules are symbiotic organs in which the Rhizobium bacterium functions as an $\mathrm{N}_{2}$-reducing cell organelle with which the plant acquires the possibility to use $\mathrm{N}_{2}$ as a nitrogen source. On most, if not all, leguminous plant roots, formation of root nodules is only possible if the roots are in a specific physiological state, with their growth being limited by a lack of combined nitrogen and with not so many root nodules already being formed that further root nodule formation is inhibited. The latter phenomenon, the inhibition of root nodule formation by already existing ones, which limits the number of root nodules per plant, is called autoregulation of nodulation (AUT) (Caetano-Anolles and Gresshoff 1991; Delves et al. 1986; Pierce and Bauer 1983).

How legumes regulate their nodule number is largely unknown. Indications for signals or factors involved in AUT

Corresponding author: Anton A. N. van Brussel;

E-mail: Brussel@rulbim.Leidenuniv.nl mainly originate from experiments with plant mutants, defective in the regulation of root nodule number, that form many more root nodules than do wild-type plants. Grafting experiments with these so-called supernodulating or hypernodulating mutants (supernodulating pea [Duc and Messager 1989], soybean [Caetano-Anolles and Gresshoff 1991; Delves et al. 1987; Francisco and Harper 1995], and Lotus japonicus [P. M. Gresshoff and A. Hussain, as cited by Beveridge 2000]) show that, in most mutants, wild-type nodulation is restored by replacing the mutant shoot with a wild-type shoot. Further, a wild-type root acquires a supernodulating phenotype when it is grafted with the shoot of such supernodulating mutants. These data lead to the conclusion that factors coming from the shoot signal the root to stop nodulation. Another class of supernodulating mutants have roots of which the nodulation phenotype does not change upon grafting with a wild-type shoot (Postma et al. 1988). Apparently, the mutation affects a root factor. From grafting experiments with more shoots or more roots on one plant (Glycine max), Sheng and Harper (1997) obtained data indicating a number of nodulation-stimulating and nodulationinhibiting shoot factors.

In roots with AUT, a variety of different stages in nodule development is present. This suggests a sudden arrest of consecutive root nodule formation. It is not known if the condition of "no nodule formation" is caused by resistance of the root against Rhizobium infections (defense), by disappearance of the sensitivity of the root for infection factors, or by lack of nodulation-promoting factors.

Study of AUT factors in a nodulated root is complicated by the difficulty of distinguishing factors involved in nodulation from factors specifically involved in AUT. In this report, we describe experiments aimed at developing a system to specifically identify factors involved in AUT. A split-root technique, as developed earlier for soybean (Kosslak and Bohlool 1984), was adapted for $V$. sativa subsp. nigra, a model plant for studies of indeterminate nodulation (van Brussel et al. 1982, 1986, 1990). After cutting the tip of the main root of germinated seedlings, several lateral roots develop. Each of two equally sized roots is incubated in a small tube contained in a larger tube (Fig. 1). In this split-root system, one root A can thus be treated separately from root $\mathrm{B}$ and at a different time. The effect of incubation of root A, with bacteria or factors playing a role in root nodule formation, on nodulation of root $\mathrm{B}$ can be studied. Questions were as follow. (i) Can AUT be induced in root B in such a way that the split-root system can be used as a representative bioassay to study factors inducing or influencing AUT? (ii) Which responses characterize AUT? (iii) Which Rhizobium factors, plant factors, or both induce AUT? 
After investigation of the optimal conditions for AUT by inoculation of root A and root B with nodulating Rhizobium bacteria, the effect of inoculation of root A with nodulation (Nod) factors was investigated. Two types of Nod factors (lipochitin oligosaccharides) of R. leguminosarum bv. viciae (Spaink et al. 1991) were used: (i) "specific Nod factors," inducing formation of root nodule primordia in $V$. sativa subsp. nigra (Nod $\operatorname{RlvIV}(\mathrm{C} 18: 4, \mathrm{Ac})$ and Nod RlvV(C18:4,Ac)) and (ii) "nonspecific Nod factors," not inducing formation of root nodule primordia but with root hair-deforming properties (Nod $\operatorname{RlvIV}(\mathrm{C} 18: 1, \mathrm{Ac})$ and $\operatorname{Nod} \operatorname{RlvV}(\mathrm{C} 18: 1, \mathrm{Ac}))$. The effect on AUT of Nod factor application to root A was compared with the effect of inoculation of root A with a noninfective Rhizobium mutant that produces normal Nod factors. Finally, the growth hormone zeatin, a cytokinin known to be implicated in root nodule formation and sink induction (Bauer et al. 1996), was tested for AUT-inducing properties.

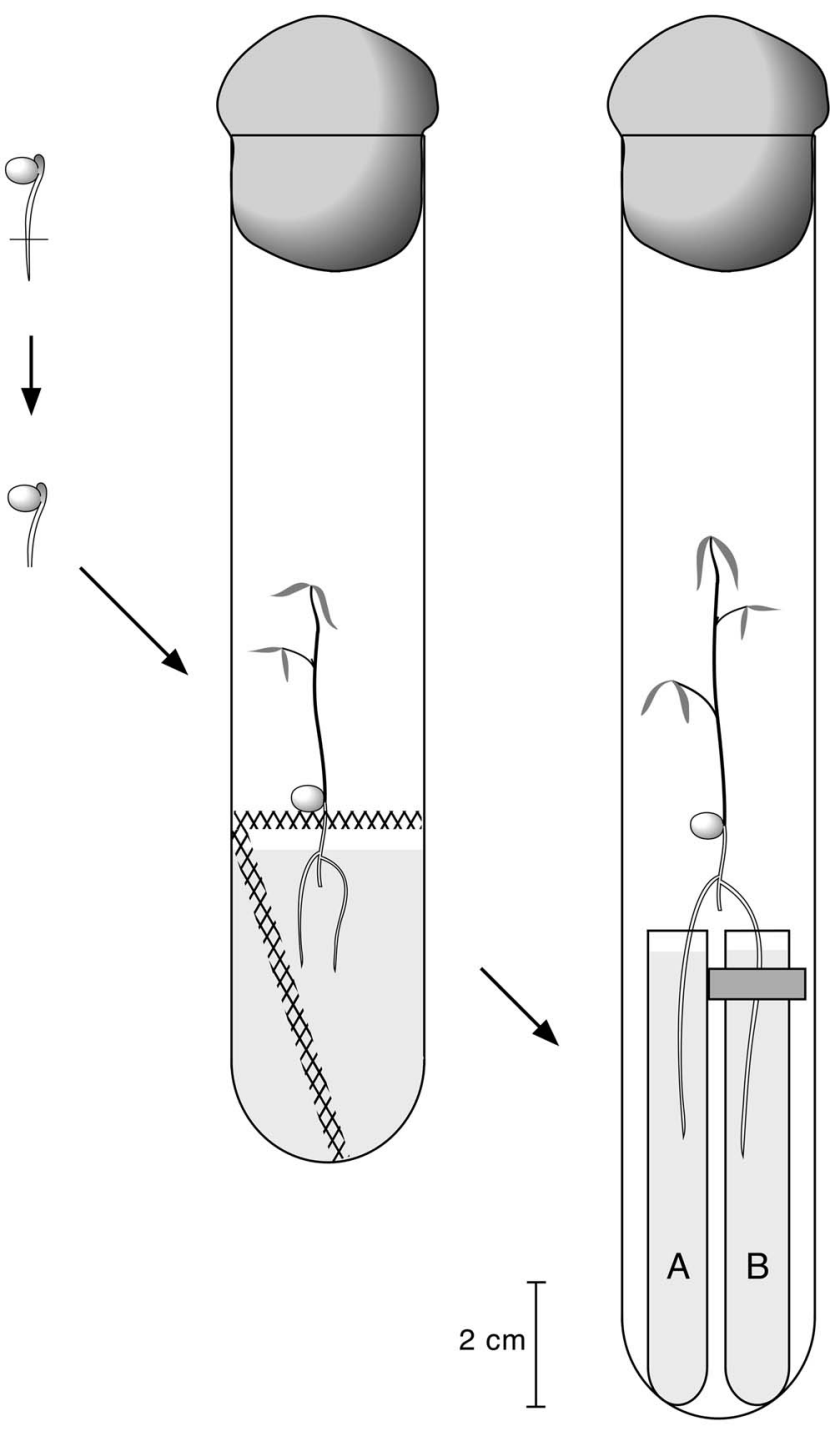

Fig. 1. Split-root practice. After cutting off the tip of the root, the Vicia seedlings are incubated in tubes containing Jensen medium. After 6 to 7 days, the plantlets having two lateral roots of equal size are transferred to split-root tubes containing two little tubes with the same medium. Root A is incubated in tube A and root B is incubated in tube B. Bacteria and/or factors (from bacteria or plants) are added to tube A 1 or 2 days later, while additions to tube $\mathrm{B}$ are made 2 days after the addition made to tube A. The experiment is ended 7 days after the additions made to tube $B$, and nodulation related data are collected.

\section{RESULTS}

Standard split-root system for $\boldsymbol{V}$. sativa subsp. nigra.

A split-root system, as schematically drawn in Figure 1, was obtained as described below. With the plants cultured in this way, a number of different AUT experiments were performed.

\section{Optimal conditions for AUT.}

Optimal conditions for AUT were investigated using weakly buffered Jensen medium. L- $\alpha$-(2-aminoethoxyvinylglycine) (AVG), an inhibitor of ethylene biosynthesis, was added to the medium to obtain a better and earlier nodulation of the Vicia roots (Zaat et al. 1989). Inoculation of root A with $10^{2}$ to $10^{3}$ nodulating Rhizobium bacteria per $\mathrm{ml}$ was optimal for nodulation of root A and for AUT on root B (Fig. 2). Thus, $10^{3}$ bacteria per $\mathrm{ml}$ was chosen for our standard AUT assay. Root nodules were observed 4 days after inoculation of root A, and approximately 16 root nodules were counted on the upper part of this root at 9 days after inoculation. On root $\mathrm{B}$, inoculated with the same Rhizobium bacteria 2 days after infection of root A, no root nodules were formed as of 7 days later (Table 1, Fig. $3)$. As a control, with the same time schedule, root A was either not inoculated or inoculated with $R$. leguminosarum strain LPR5045, a Rhizobium strain without a Sym(biosis) plasmid. In these cases, root B formed about eight nodules (Table 1, Fig. 3 ). This smaller number of nodules as compared with the nodulation of root $\mathrm{A}$ is due to the 2-day-older age of root $\mathrm{B}$ at the time of inoculation in this culture system.

These results demonstrate that the Vicia split-root system can be used as a system to study AUT at early stages of root nodulation.

\section{Timing of AUT.}

In order to determine the amount of time required for the development of the nonnodulating condition of root $\mathrm{B}$, this root was inoculated at several different time intervals after the inoculation of root A, under weakly buffered conditions. As illustrated in Figure 4, a strong inhibition of nodulation of root B was already apparent when root B was inoculated $30 \mathrm{~h}$ after the inoculation of root $\mathrm{A}$, whereas $48 \mathrm{~h}$ was sufficient to give $100 \%$ AUT (no nodules) on root B. Therefore, in further ex-

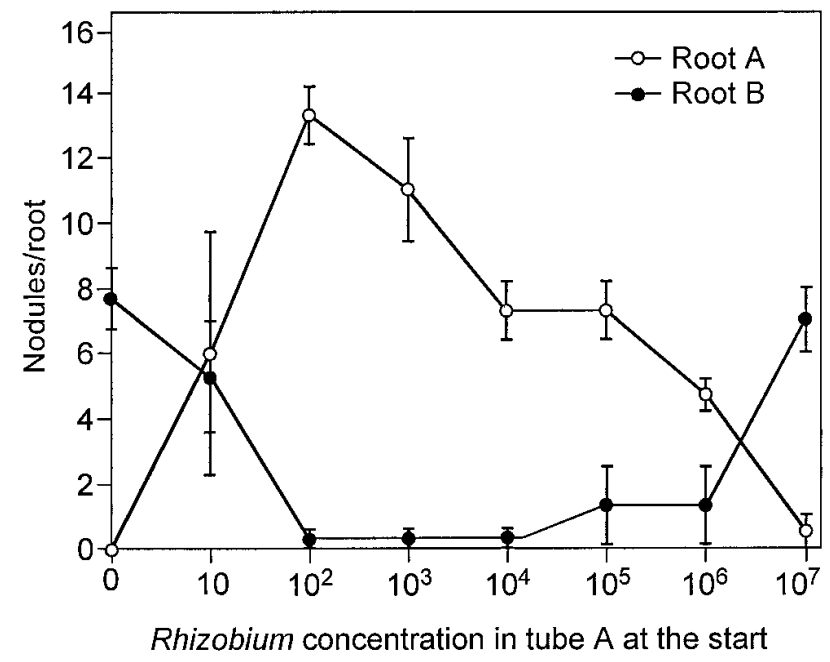

Fig. 2. Nodulation and autoregulation in the split-root system under weakly buffered conditions. Effect of the Rhizobium number (CFU/ml), just after inoculation of tube A, on nodulation (roots A and B) and autoregulation (root B). Incubation of root B with $10^{3}$ Rhizobium bacteria per $\mathrm{ml}$ was 2 days after inoculation of root $\mathrm{A}$. Open circles $=\operatorname{root} \mathrm{A}$ and filled circles $=$ root $\mathrm{B}$. Both tubes were inoculated with nodulating Rhizobium leguminosarum strain RBL5601. 
periments, a delay of $48 \mathrm{~h}$ between inoculation of root $\mathrm{A}$ and root B was applied.

\section{Evaluation of Rhizobium populations in B-root medium.}

Because AUT possibly can be induced by the secretion of root products that influence bacterial growth and vitality, population densities of Rhizobium bacteria in B-root medium were investigated at different time intervals, under weakly buffered conditions. After inoculation of root A with the nonnodulating $R$. leguminosarum strain LPR5045, B-root media sustained a normal development of the bacterial population growing from $10^{3}$ bacteria per $\mathrm{ml}$ at the time of inoculation to $2 \times 10^{6}$ bacteria per $\mathrm{ml} 5$ days later (Fig. 5). In contrast, in medium of a root $\mathrm{B}$ autoregulated by the incubation of root $\mathrm{A}$ with the nodulating $R$. leguminosarum strain RBL5601, the population density decreased to less than 20 viable cells per ml at day 3 or 4 after inoculation with $10^{3}$ Rhizobium cells per ml at day 0 (Fig. 5). In the medium of root $\mathrm{A}$, the population density reached approximately $2 \times 10^{6}$ Rhizobium cells per $\mathrm{ml}$, either with strain LPR5045 or with strain RBL5601. This bacterial population density is normal for a Vicia culture in Jensen medium.

Samples taken from uninoculated, autoregulated B-root medium (root $\mathrm{A}$ was inoculated with nodulating bacteria, root $\mathrm{B}$ was not inoculated) retained the growth inhibition properties even after addition of a $10^{-3}$ volume of "B medium" (a minimal medium for bacterial growth) but not after addition a $10^{-2}$ volume of B medium. Normally, in the absence of autoregulated root exudate, $10^{-3}$ dilution in water of this $\mathrm{B}$ medium is already sufficient to sustain growth of the bacteria. Therefore, since the concentration of the buffer in the $10^{-2}$ dilution of this medium is 10 times larger, this suggests that growth does not occur because of an unsuitable $\mathrm{pH}$ of the medium.

Efforts to concentrate a putative bacterial growth-inhibiting factor by freeze-drying were unsuccessful, since no growthinhibiting substance was recovered from the residue.

\section{Acidification of autoregulated B-root exudate.}

Remarkably, under weakly buffered conditions, split-root plants with AUT showed a difference in size between root A and root B at day 7 (Fig. 3). The root first inoculated with nodulating bacteria (root A) was much longer and thicker than root $\mathrm{B}$, which was infected 2 days later with the same bacteria (Fig. 3, plant on left). When, instead, root A was inoculated with Sym-plasmid-minus bacteria, then root B inoculated with nodulating bacteria 2 days later became much thicker than root A (Fig. 3, plant on right). It seemed as if the root (first) inoculated with nodulating bacteria becomes a sink, at the expense of the other root. At the same time, or alternatively, appearance of AUT can be correlated with production of a growth-inhibiting factor. Measurement of the $\mathrm{pH}$ of the autoregulated B-root medium (Fig. 6) showed a much lower $\mathrm{pH}$ value than that of the A-root medium of the same plant. Buffering of this acidified exudate to $\mathrm{pH} 5.6$ (10 $\mathrm{mM}$ morpholinoethanesulfonic acid [MES] buffer) not only restored normal root growth but also prevented strong growth inhibition of Rhizobium bacteria. Acidification of B-root medium appeared to be induced by in-

Table 1. Autoregulation of nodulation induced by Rhizobium bacteria

\begin{tabular}{lcc}
\hline Root A with & $\begin{array}{c}\text { Nodules per root } \\
\text { root A }\end{array}$ & $\begin{array}{c}\text { Nodules per root } \\
\left.\text { root B (Rhizobium } \text { Sym }^{+}\right)\end{array}$ \\
\hline Rhizobium $\mathrm{Sym}^{+}$ & $15.7( \pm 2.8)^{\mathrm{b}}$ & 0 \\
Rhizobium $\mathrm{Sym}^{-}$(control) & 0 & $7.8( \pm 4.6)^{\mathrm{b}}$ \\
\hline
\end{tabular}

${ }^{a}$ Rhizobium $\mathrm{Sym}^{+}$means Rhizobium bacteria with the symbiosis plasmid pRL1JI, producing Nod factors. Rhizobium Sym ${ }^{-}$means Rhizobium bacteria without the symbiosis plasmid pRL1JI, not producing Nod factors.

${ }^{\mathrm{b}}$ The values between parentheses are standard deviations. cubation of root A with nodulating Rhizobium bacteria (Fig. 6A) or with Nod factors (Fig. 6B). Both types of Nod factors, the specific Nod factors, which induce formation of root nodule primordia in Vicia roots, and the nonspecific Nod factors, which do not induce the formation of root nodule primordia in Vicia roots, induced a similar acidification (data not shown for nonspecific Nod factors). In these cases, the $\mathrm{pH}$ of the A-root medium, which did not cause bacterial growth inhibition, acidified much less than that of the B-root exudate, resulting in a difference of about $1 \mathrm{pH}$ unit between the media of both roots. Acidification was not induced by Rhizobium bacteria cured of the pRL1JI Sym plasmid (strain LPR5045) (Fig. 6A).

These results suggest that inhibition of nodulation of root $\mathrm{B}$ in a split-root system is caused by acidification of B-root medium, which inhibits bacterial growth.

Inhibition of nodulation and acidification caused by zeatin.

Because cytokinins are known to play a role in nodulation and sink induction (Bauer et al. 1996) and because sink induction seems to occur in the inoculated root $\mathrm{A}$, this root was incubated with the cytokinin zeatin in order to test the effect on

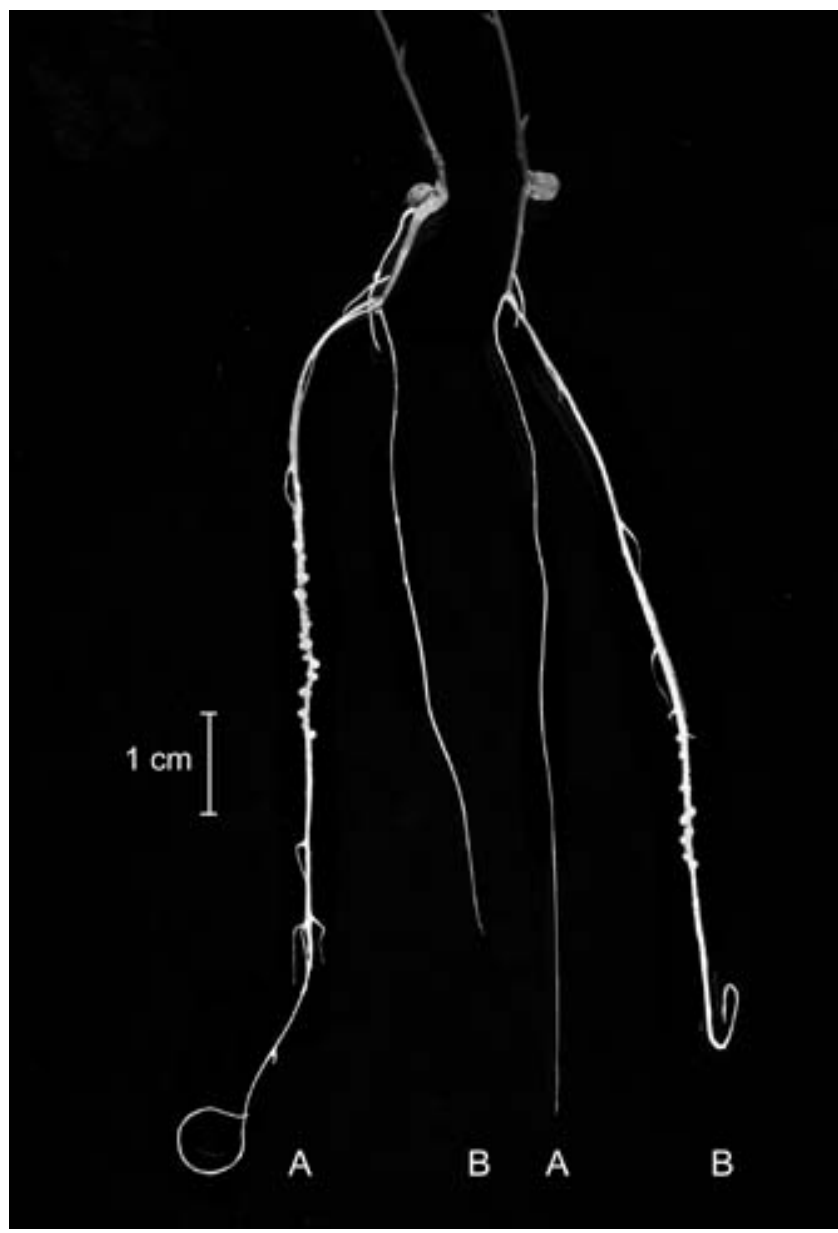

Fig. 3. Autoregulation of Vicia sativa subsp. nigra in the split-root system under weakly buffered conditions. Roots A (left side) were incubated 2 days earlier than roots $\mathrm{B}$ (right side). The plant on the left was incubated (both roots) with the nodulating Rhizobium leguminosarum strain RBL5601. Of the control plant (right), root A was incubated with $R$. leguminosarum strain LPR5045 (without Symbiosis plasmid pRL1JI) and root B with $R$. leguminosarum strain RBL5601. An earlier incubation of root $\mathrm{A}$ with a nodulating bacterium inhibits nodulation of $\operatorname{root} \mathrm{B}$, while incubation of root $\mathrm{A}$ with a bacterium without nodulation genes does not inhibit nodulation of root B. Note the difference in size (length and thickness) of the roots, which indicates "sink" formation in the nodulated roots. 
nodulation of root $\mathrm{B}$ under weakly buffered conditions. Incubation of root $\mathrm{A}$ with $2 \times 10^{-7} \mathrm{M}$ zeatin induced a Nod-minus phenotype on root B (data not shown). Furthermore, incubation of root A with zeatin induced a significant acidification of the weakly buffered medium of root B (Fig. 6C).

Incubation with $2 \times 10^{-7} \mathrm{M}$ zeatin induced formation of a very thick root $\mathrm{A}$, while root $\mathrm{B}$ in the absence of zeatin remained thin and mostly shorter than root A (Fig. 7). Microscopic examination, after fixation and clearing of the roots, revealed many cell divisions mainly in the inner cortex of the root. After staining with Lugol's solution, a strong accumulation of starch grains (Fig. 7) was found, also mainly in the inner cortex (data not shown). In root B of these plants, the inner cortex lacked this accumulation of starch grains and no cell divisions were seen. The observations were the same regardless if weakly buffered or strongly buffered conditions were used.

\section{Autoregulation in strongly buffered Jensen medium.}

In order to test the importance of medium acidification during AUT, the experiments were repeated with Jensen medium strongly buffered at $\mathrm{pH} 5.6$ with $10 \mathrm{mM}$ MES buffer, from which the deposit was not removed. A pH value of 5.6 was found to be optimal for infection of Vicia roots (data not shown). Root A was treated with nodulating R. leguminosarum strain RBL5601 or nonnodulating $R$. leguminosarum strain LPR5045. Figure 8 shows that incubation of root A with the nodulating Rhizobium bacteria caused a $100 \%$ AUT of root B. The negative control, inoculation with the nonnodulating strain, did not show AUT.

Interestingly, incubation of root A with zeatin under these strongly buffered conditions did not induce AUT on root B, since these roots had the same number of nodules (five or six per plant) regardless of incubation of root $\mathrm{A}$ with or without zeatin. This means that, most probably, acidification induced by zeatin under weakly buffered conditions leads to bacterial growth inhibition, causing inhibition of nodulation of root B, which is prevented under strongly buffered conditions.

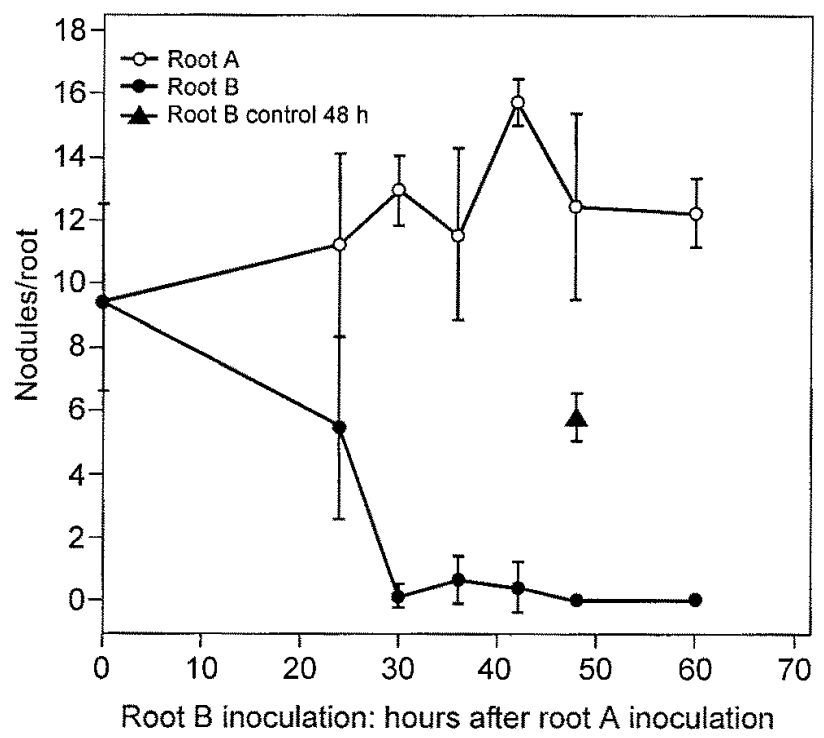

Fig. 4. Time required for the autoregulation response in the split-root system under weakly buffered conditions. Root B (filled circles) was incubated with the nodulating Rhizobium leguminosarum strain RBL5601 at different time intervals after inoculation of root A (open circles) with the same strain. The control (filled triangle): root B inoculated with $R$. leguminosarum strain RBL5601, $48 \mathrm{~h}$ after inoculation of root A with $R$. leguminosarum strain LPR5045 (without Symbiosis plasmid pRL1JI).
Autoregulation induced by Nod factors.

Root nodule primordia, preinfection threads, and root hair deformation can be induced in Vicia roots by Nod factors produced by $R$. leguminosarum bv. viciae (van Brussel et al. 1992). With the exception of root hair deformation, which is already visible 1 day after inoculation, preinfection threads and nodule primordia in Vicia roots can be observed after 3 days at the earliest. In order to more specifically analyze AUT-inducing factors and the AUT phenotype, we applied strongly buffered conditions in the following split-root experiments. Root A was incubated with specific Nod factors at a concentration of $10^{-7} \mathrm{M}$. Two days later, root $\mathrm{B}$ was inoculated with nodulating Rhizobium bacteria, and nodulation on root B was scored another 7 days later. Root B showed $50 \%$ of the nodules of the negative control value (Fig. 9), thus AUT was only $50 \%$. The same result was found when root A was inoculated with the normally specific Nod factor-producing but noninfective exopolysaccharide-deficient strain RBL5833 (van Workum et al. 1997) (Fig. 9). Incubation of root A with nonspecific Nod factors, which do not induce nodule primordia, only induced marginal AUT and only at a rather high concentration $\left(10^{-6} \mathrm{M}\right)$ (data not shown). These results demonstrate that not only do specific Nod factors of $R$. leguminosarum bv. viciae induce AUT but also that rhizobial infection is required for complete autoregulation.

\section{Anatomical features of AUT on Vicia roots.}

In order to investigate the developmental stage at which nodulation was inhibited at AUT, autoregulated roots B, incubated with nodulating Rhizobium bacteria 2 days after incubation of root A, were examined by microscopy. In weakly buffered Jensen medium, root B was inhibited in its growth, most probably by acidification, and root hairs were almost absent. Under these conditions, symbiotic phenotypes other than some root hair deformations were not seen and the roots remained thin. Under strongly buffered conditions, roots B had deformed root hairs but did not show infected root hairs or infection threads. Moreover, nodule primordial bumps such as those that were seen below the zone of nodulation of root A could be observed on root $\mathrm{B}$, however, they were in a small zone (data not shown). Also, under these strongly buffered conditions, roots B often are thicker than uninfected autoregulated roots $\mathrm{B}$, indicating some sink effect induced by a nodulating Rhizobium bacterium.

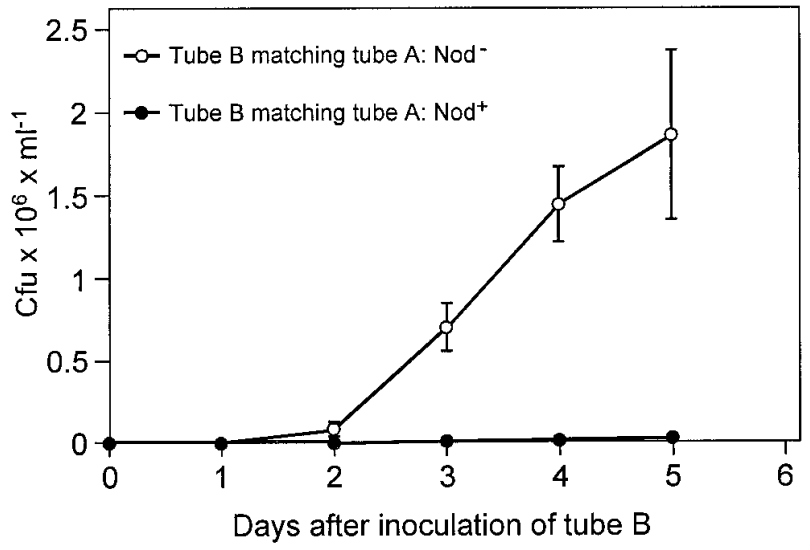

Fig. 5. Growth of the Rhizobium population in tube B of the split-root system under weakly buffered conditions. Inoculation of root B with the nodulating Rhizobium leguminosarum strain RBL5601 ( $\left.\mathrm{Nod}^{+}\right)$was 2 days after inoculation of root $\mathrm{A}$ with the same strain (filled circles) or $R$. leguminosarum strain LPR5045 $\left(\mathrm{Nod}^{-}\right.$, without Symbiosis plasmid pRL1JI, open circles). 
These results show that nodulation of root B is arrested at a developmental stage that is reached 3 days after its inoculation. This coincides with nodule meristem formation and growth of young nodules in root $\mathrm{A}$ (inoculated 2 days earlier).

\section{DISCUSSION}

AUT or feedback regulation of nodulation is defined as systemic inhibition of nodulation by already existing or earlier induced root nodules (Caetano-Anolles and Gresshoff 1991; Delves et al. 1986; Pierce and Bauer 1983). Thus, inhibition of root nodule formation on root B in a split-root system by a 2day-earlier incubation of root A with nodulating Rhizobium bacteria can be considered by definition as AUT. Optimal systemic inhibition of B-root nodulation in the Vicia system as described here required incubation of root $\mathrm{A}$ with a low number of Rhizobium bacteria (Fig. 2, $10^{3}$ cell per $\mathrm{ml}$ ) and the presence of the ethylene inhibitor AVG. The same conditions were required for optimal nodulation of root A. As can be seen in Figure 2, inoculation of root A with a large number of Rhizobium bacteria causes an inhibition of nodulation on root $\mathrm{A}$ and a "restoration" of nodulation on root B. How incubation of root A with a large number of Rhizobium bacteria causes inhibition of nodulation on this root will be the subject of further research. However, this observation illustrates the quantitative aspect of AUT: less nodules on root A give more nodules on root B.

In our experiments, the roots were not shielded from light. For $V$. sativa subsp. nigra, this means that incubation with nodulating bacteria, or Nod factors, results in a stress reaction visible as thick and short roots, the Tsr phenotype (van Brussel et al. 1986; Zaat et al. 1989). Under these circumstances, nodules appear only 10 to 12 days after infection with Rhizobium bacteria, which makes it impossible to work in small volumes because of changes in the plant growth medium occurring at longer incubation. AVG, an inhibitor of ethylene synthesis (van Workum et al. 1995; Zaat et al. 1989), was applied to prevent the Tsr phenotype caused by a combined effect of light and Nod factors. AVG addition results in normal root morphology and better and earlier nodulation (nodules are visible as early as 4 days after inoculation), required for a split-root system applicable to AUT research.

Since AVG was added to tube A and tube B at the moment of infection with nodulating Rhizobium bacteria, a role for ethylene biosynthesis in the inhibition of nodulation of root $\mathrm{B}$ can be excluded in our experiments. Like in roots of other legumes, including Vicia roots, Medicago truncatula roots show that only a limited number of root nodules develop from the many infection centers formed in the susceptible zone after infection with Sinorhizobium meliloti. The sickle mutant of this plant forms many more nodules in the susceptible root zone, and this mutation is further characterized by an insensitivity of the plant to ethylene. Therefore, it was proposed that ethylene plays a role in negatively regulating the number of root nodules that develop from infection centers in the susceptible zone (Penmetsa and Cook 1997). This conclusion is strengthened by our finding that $V$. sativa subsp. nigra (with the roots grown in darkness) forms twice as much nodules when AVG is added to the growth medium (A. A. N. van Brussel, T. Tak, K. J. M. Boot, and J. W. Kijne, unpublished data). Wopereis and colleagues (2000) differentiate between the effect of ethylene on nodule number in the susceptible zone and a spatial and temporal control of root susceptibility to nodulation. The latter control results in inhibition of nodule formation on younger root tissues by prior nodulation events in older root regions, and Wopereis and colleagues (2000) correctly call only this latter type of inhibition AUT. Use of AVG in our split-root experi- ments excluded negative ethylene effects on nodulation. Therefore, inhibition of nodulation on root $\mathrm{B}$ must be considered AUT according to the latter definition. Interestingly, as the effects of the formation of the first root nodules on AUT are

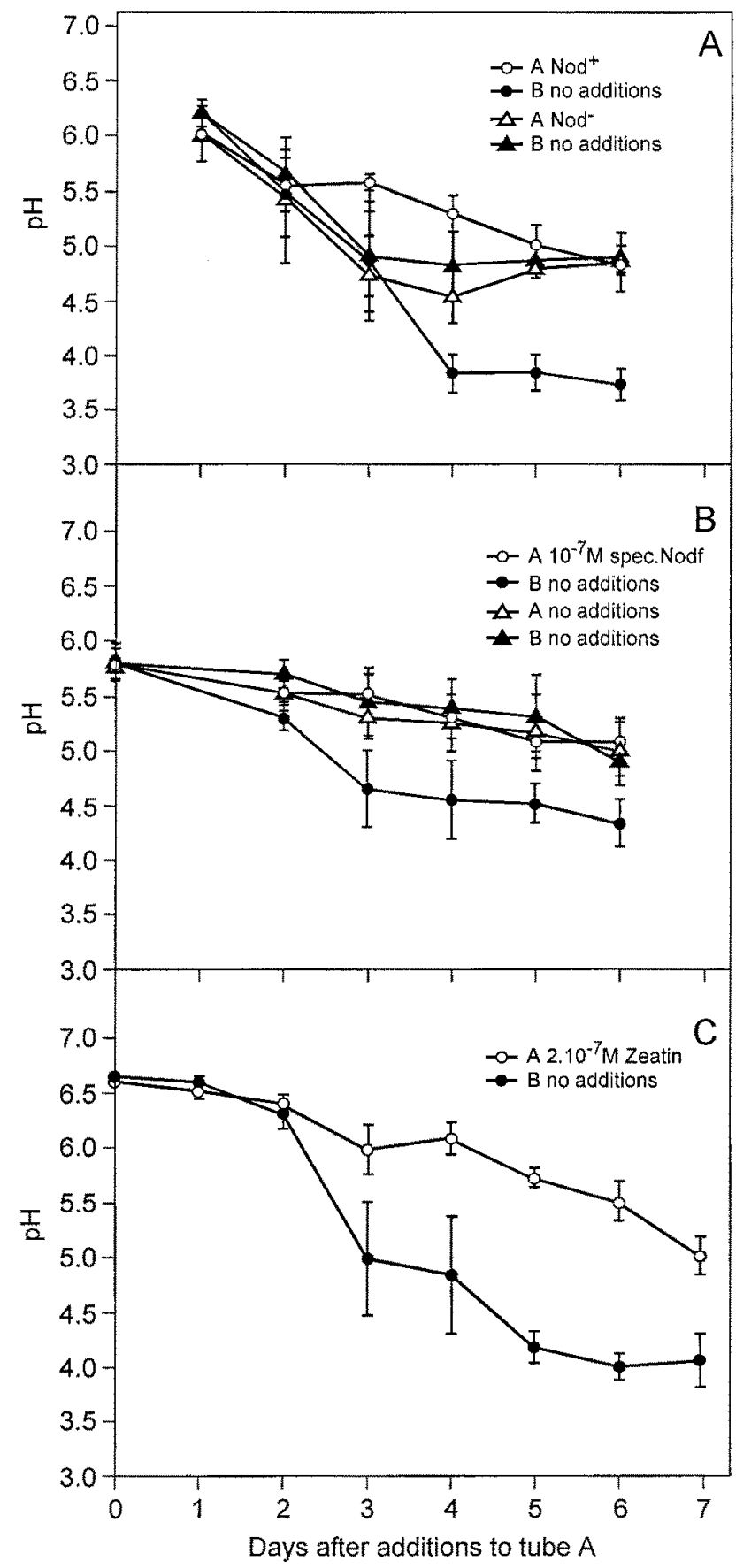

Fig. 6. Medium acidification in tube A and tube B of the split-root system under weakly buffered conditions. Effect of addition to tube A of A, Rhizobium bacteria; B, $10^{-7} \mathrm{M}$ specific Nod factor (spec. Nodf.); or C, $2 \times 10^{-7}$ $\mathrm{M}$ zeatin. A, The $\mathrm{pH}$ in tube $\mathrm{A}$ inoculated with the nodulating R. leguminosarum strain RBL5601 ( $\mathrm{Nod}^{+}$, open circles) and the $\mathrm{pH}$ of matching root B (uninfected, filled circles). The $\mathrm{pH}$ in tube A inoculated with $\mathrm{R}$. leguminosarum strain LPR5045 ( Nod $^{-}$, without a Symbiosis plasmid, open triangles) and the $\mathrm{pH}$ in matching tube $\mathrm{B}$ (uninfected, filled triangles). $\mathbf{B}$, The $\mathrm{pH}$ in tube $\mathrm{A}$ after addition of spec. Nodf. in Chaps (open circles) and the $\mathrm{pH}$ in matching tube $\mathrm{B}$ (without additions, filled circles). The $\mathrm{pH}$ in tube $\mathrm{A}$ (no Nod factor addition, only Chaps, open triangles) and the $\mathrm{pH}$ in matching tube $\mathrm{B}$ (no additions, filled triangles). $\mathbf{C}$, The $\mathrm{pH}$ in tube $\mathrm{A}$ after addition of a nodulation-inhibiting concentration of zeatin $\left(2 \times 10^{-7} \mathrm{M}\right.$, open circles) and the $\mathrm{pH}$ in matching tube $\mathrm{B}$ (no additions, filled circles). 
studied, the very early stages of AUT can also be studied with this Vicia split-root system.

\section{Plant signals involved in AUT.}

With two different culture conditions, we found inhibition of B-root nodulation after incubation of root $\mathrm{A}$ with nodulating bacteria under weakly buffered conditions, in which the B-root medium acidified to around $\mathrm{pH} \mathrm{4}$, and under strongly buffered conditions, in which B-root nodulation is inhibited without acidification of the B-root medium. Interestingly, in a plant with strongly acidified B-root medium, root A does not acidify its medium as much. In A-root medium, bacterial population densities go up to about $2 \times 10^{6}$ per $\mathrm{ml}$, and this root seems to function normally as it, as well as its root nodules, continues growing. Still, the younger part of root A is autoregulated. This already indicates that medium acidification is not an essential element of AUT. Apparently, acidification of the B-root medium is a side effect caused by the split-root system, which happens to inhibit nodulation. However, the fact remains that this effect requires systemic signaling from root $\mathrm{A}$ to root $\mathrm{B}$.

Acidification of B-root medium could also be induced by incubation of root A with (i) specific Nod factors (Fig. 6B), (ii) nonspecific Nod factors (data not shown), and (iii) the cytokinin zeatin (Fig. 6C), the latter with concomitant inhibition of nodulation of root B. Under strongly buffered conditions, however, zeatin addition to root A did not cause AUT on root B. This means that nodulating bacteria induce at least two sys-

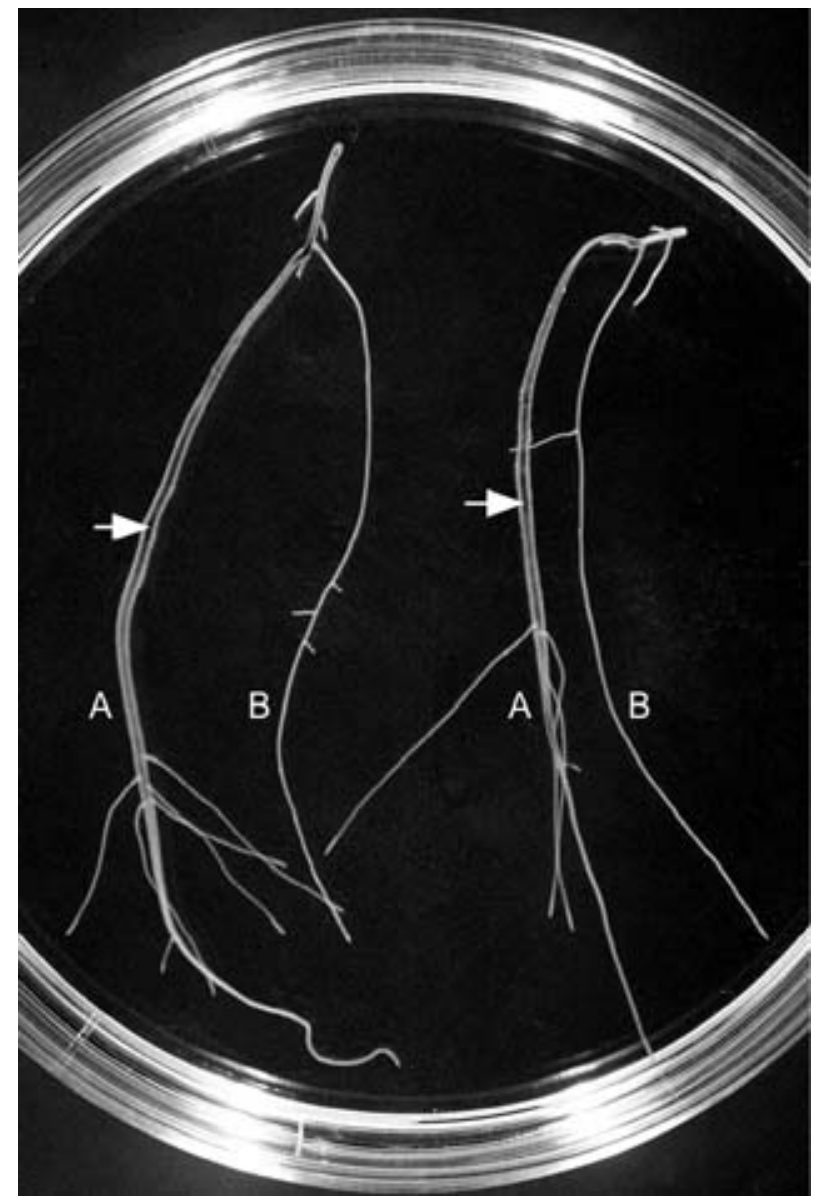

Fig. 7. Split-root systems of which only root A was incubated with $2 \times$ $10^{-7} \mathrm{M}$ zeatin. The root system was cleared 9 days later with hypochlorite solution and stained with Lugol's solution. The dark blue staining of starch grains in the inner cortex was only observed in root A and is seen in this figure as the dark inner part of the roots A (arrow). temic signals, signal 1 inducing acidification of B-root medium, mimicked by the addition of cytokinin to root A, and signal 2 specifically inducing AUT.

Incubation of root $\mathrm{A}$ with zeatin induced a thickening of this root, whereas at the same time, thickening of root B was not observed (Fig. 7). Microscopic examination revealed that, in the presence of zeatin, cell divisions (data not shown) and starch accumulation (Fig. 7) were induced mainly in the inner cortex of root A and not in root B (data not shown). A similar thickening of root A took place upon infection of this root with nodulating bacteria (Fig. 3), which locally induced cell divisions, as well as starch accumulation, at sites of root nodule primordium formation in the inner cortex. Apparently, zeatin induces a sink in root $\mathrm{A}$, and acidification of B-root medium may be related to this sink formation. Signals from the shoot, induced by the zeatin signal from root A, may elicit abnormal growth factor ratios in root B (where no zeatin is added), which may result in acid secretion.

It has been suggested by many authors that cytokinin is involved in the induction of nodular cell divisions. Cytokinin is required for root cortical cell divisions (Libbenga et al. 1973; Smit et al. 1995), and secretion of zeatin by bacteria can lead to the formation of pseudonodules (Cooper and Long 1994). Furthermore, expression of early nodulin genes, such as MsEnod12A and Enod40, which is induced by application of Nod factors to the root, is also induced by zeatin (Bauer et al. 1996; Mathesius et al. 2000). Bauer and colleagues (1996) found that treatment of alfalfa roots with Nod factors or zeatin induced similar patterns of cortical cell division, induction of MsEnod12 expression, and amyloplast accumulation. They suggested that Nod factors and cytokinins share elements of their signal transduction pathways to the inner root cortex and to sink formation. These observations are now extended with our finding that zeatin and Nod factors both induce acidification of B-root exudate, which suggests signaling from root to shoot and from shoot to other roots. Zeatin signaling is clearly different from Nod factor signaling in the sense that it does not result in AUT in buffered Jensen medium. Nod factor application may induce zeatin production, and acidification of the Broot medium by Nod factor application on root A may result

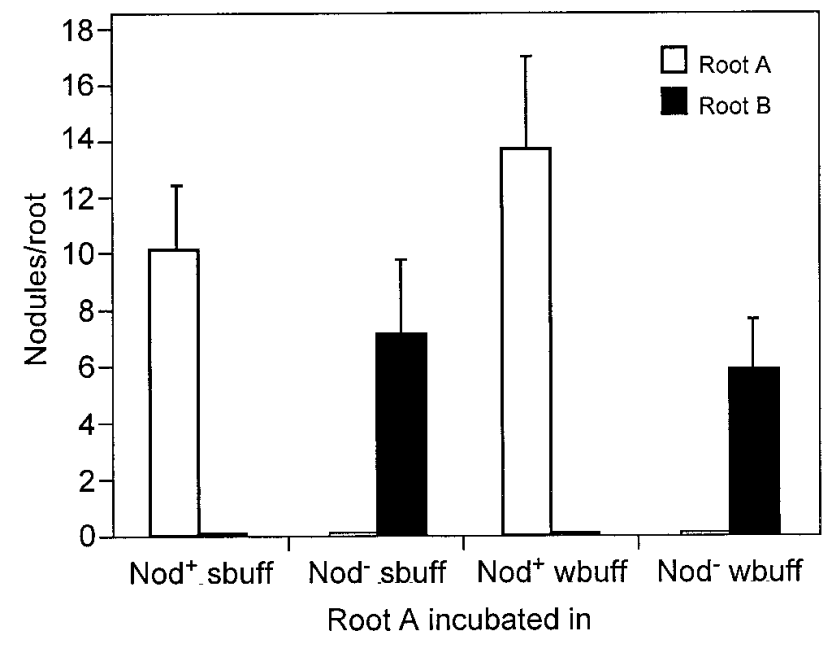

Fig. 8. Autoregulation in the split-root system with strongly buffered (sbuff) and weakly buffered (wbuff) media. The bars in the graph represent the number of nodules (7 days after B-root inoculation) on pairs of root A (white bars) and matching root B (black bars). Nod ${ }^{+}$indicates inoculation with the nodulating Rhizobium leguminosarum strain RBL5523 and $\mathrm{Nod}^{-}$indicates inoculation with $R$. leguminosarum strain LPR5045 (without a Symbiosis plasmid). Root B was inoculated 2 days after inoculation of root A. 
from this effect. Wopereis and colleagues (2000) found that the root length of the supernodulating L. japonicus mutant harl-1, carrying shorter roots than wild-type plants, could partly be restored by application of zeatin to the medium. This is another indication that zeatin signaling and AUT signaling are interwoven.

\section{Rhizobium factors inducing AUT.}

Nonspecific Nod factors induce root hair deformation but not formation of root nodule primordia and preinfection threads (Spaink et al. 1991; van Brussel et al. 1992). Nonspecific Nod factors only induced marginal AUT at a rather high concentration $\left(10^{-6} \mathrm{M}\right)$. However, acidification of B-root exudate was significantly induced by nonspecific Nod factors (the same values as shown in Fig. 6B). This is consistent with the observation that nonspecific Nod factors inhibit auxin transport capacity of Vicia roots (Boot et al. 1999), induce starch accumulation in the inner cortex, and activate inner cortical cells (A. A. N. van Brussel, T. Tak, K. J. M. Boot, and J. W. Kijne, unpublished data). Apparently, nonspecific Nod factors induce the sink situation in root $\mathrm{A}$, which is connected to acidification of B-root medium.

In contrast to nonspecific Nod factors, specific Nod factors induce formation of preinfection threads and nodule primordia (Spaink et al. 1991; van Brussel et al. 1992). Obviously, these responses are coupled with AUT; however, in this case, AUT is only $50 \%$. Complete $100 \%$ is only obtained after infection of $V$. sativa subsp. nigra roots with nodulating Rhizobium bacteria. This probably results from the combined effects of formation of root nodule primordia, presence of root nodule meristems, and formation of infection threads, either alone or in combination, in these Vicia roots. Young growing nodules may absorb factors or secrete signals that are necessary for the maintenance of AUT. Removal of nodules relieves AUT, resulting in new nodules being formed (Caetano-Anolles and Gresshoff 1991). In Vicia roots, specific Nod factors do not induce nodule structures beyond the stage of nodule primordia, in which cell division stops after some time. This accentuates the importance of the presence of dividing cells in a nodule meristem (induced by infection with nodulating rhizobia) for induction of complete AUT.

The Vicia split-root system can be used for experiments in which systemic and nonsystemic effects of various bacterial and chemical factors on nodulation are investigated. We have demonstrated the existence of two signaling systems related to AUT, (i) a sink-related system that can be induced by addition of cytokinin or nonspecific Nod factors, and (ii) a specific AUT-inducing system for which formation of new nodule cells (cell divisions) in nodule primordia or nodule meristems seems to be required. In a mono-root system, these findings would have been more difficult to make. With the use of this splitroot system, comparative genomics, proteomics, and metabolics of roots B with and without AUT will reveal genes and signals involved in AUT.

\section{MATERIALS AND METHODS}

\section{Bacterial strains and growth conditions.}

Rhizobium strains used in this study are (i) LPR5045 (Hooykaas et al. 1982), which is R. leguminosarum bv. trifolii strain RCR5 cured of its Sym plasmid and rifampicine resistant; (ii) RBL5515 (Priem and Wijffelman 1984), which is strain LPR5045 with an addition of streptomycin resistance; (iii) RBL5523 (van Workum et al. 1998), which is strain RBL5515 containing the bv. viciae Sym plasmid pRL1JI::Tn1831, which gives spectinomycin resistance; (iv) RBL5505 (Priem and Wijffelman 1984), which is strain
LPR5045 with an addition of streptomycin and spectinomycin resistance; (v) RBL5601 (Wijffelman et al. 1985), which is strain RBL5505 containing the bv. viciae Sym plasmid pRL1JImep2::Tn5, which gives kanamycin resistance; (vi) RBL5833 (van Workum et al. 1997), which is strain RBL5523 with a Tn5 mutation in the pss $\mathrm{D}$ gene, which gives this strain kanamycin resistance and an exopolysaccharide (EPS)-deficient, infection-minus character; and (vii) RBL5602 (Wijffelman et al. 1985), which is strain RBL5505 containing the bv. viciae Sym plasmid pRL1JInodE1::Tn5, which gives kanamycin resistance.

Media used were (i) yeast-mannitol broth (YMB) medium (Hooykaas et al. 1982); (ii) B medium, which is a minimal medium with mannitol as the only carbon source and nitrate as the only nitrogen source (van Brussel et al. 1977) and was used to produce Nod factors (Spaink et al. 1991); and (iii) tryptoneyeast extract (TY) medium (van Brussel et al. 1982). The strains were grown on agar media containing antibiotics with the following concentrations: kanamycin $(50 \mu \mathrm{g} / \mathrm{ml})$, spectinomycin $(400 \mu \mathrm{g} / \mathrm{ml})$, streptomycin $(500 \mu \mathrm{g} / \mathrm{ml})$, and rifampicin $(20 \mu \mathrm{g} /$ $\mathrm{ml})$. Before inoculation on plants, the bacteria were suspended in sterile water from fresh YMB medium plates that did not contain antibiotics. Bacterial numbers in plant growth medium were determined by plating on TY medium.

\section{Seed disinfection and germination.}

$V$. sativa subsp. nigra seeds were disinfected and germinated according to a slight variation of a method previously published (van Brussel et al. 1986) as follows. (i) The seeds were incubated in sulfuric acid (40 min) to weaken the seed coat. (ii) After extensive washings with water, the seeds were incubated for $10 \mathrm{~min}$ in commercial bleach containing sodium hypochlorite ( $4 \%$ active chloride). (iii) After two washes with water, the seeds were left overnight in water for imbibition (this water still contained sufficient bleach to smell it, which was important to kill all remaining living bacteria). (iv) The seeds were then spread on Jensen medium agar plates (a mineral medium

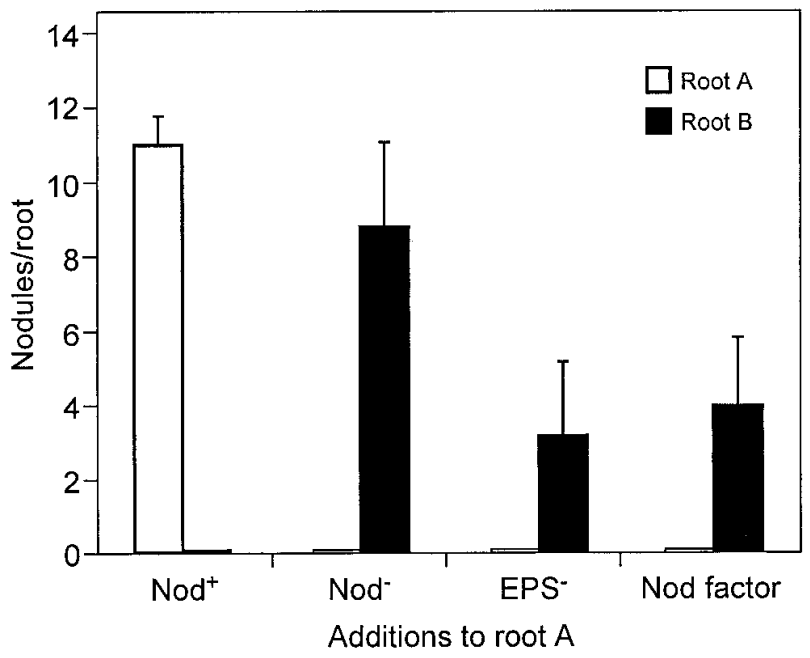

Fig. 9. Autoregulation under strongly buffered conditions by specific Nod factors and a Rhizobium strain deficient in exopolysaccharide (EPS) production and unable to form infection threads. The bars in the graph indicate pairs of root A (white bars) and matching root B (black bars). $\mathrm{Nod}^{+}$indicates inoculation with the nodulating Rhizobium leguminosarum strain RBL5523. Nod indicates incubation with the Sym-plasmidminus strain LPR5045. EPS ${ }^{-}$indicates incubation with the EPS ${ }^{-}$Inf $^{-} R$. leguminosarum strain RBL5833 (containing a Symbiosis plasmid with a complete set of nod genes and normally producing Nod factors). Nod factor indicates incubation with $10^{-7} \mathrm{M}$ specific Nod factors. The roots B were inoculated with the nodulating strain RBL5523, 2 days after additions to $\operatorname{root} \mathrm{A}$. 
without carbon and fixed nitrogen source) (Vincent 1970) wrapped in aluminum foil and, with the plates upside down, incubated in the refrigerator for at least 7 days. Depending on the stage of germination, the seedlings were incubated overnight at room temperature or at $28^{\circ} \mathrm{C}$. The next morning, most seedlings had roots about $1.5 \mathrm{~cm}$ long and could be used for tests.

\section{Split-root technique (Fig. 1).}

Lateral root formation was stimulated by cutting the tip of the main root of seedlings. The seedlings were then incubated in tubes with $25 \mathrm{ml}$ of Jensen medium (Vincent 1970), three seedlings per tube (more seedlings lead to slower root growth). Two variations of Jensen medium were used: (i) Jensen medium from which the depot was removed, called "weakly buffered Jensen medium," and (ii) Jensen medium to which $10 \mathrm{mM}$ MES buffer (no. 194835; ICN Biomedicals Inc., Zoetermeer, The Netherlands) was added and the $\mathrm{pH}$ adjusted to 5.6, called "strongly buffered Jensen medium." The decapitated roots were hanging down in the plant growth medium from stainless steel grids, which retained the cotyledons above the medium surface. The tubes were incubated ( $\pm 3 \mathrm{~cm}$ apart) in the plant growth cabinet with a temperature of $20^{\circ} \mathrm{C}, 70 \%$ relative humidity, and a 16-h-light/8-h-dark regime. The light intensity was $220 \mu \mathrm{E} \mathrm{m}^{-2} \mathrm{~s}^{-1}$ on the table surface from Philips TLD 50W/83HF fluorescent tubes (Philips, Eindhoven, The Netherlands). Approximately 1 week later (6 or 7 days), lateral roots of sufficient length $( \pm 3 \mathrm{~cm})$ had been formed and plants having two lateral roots of approximately equal size were chosen for mounting in split-root tubes (Fig. 1). Each of these two lateral roots, root $\mathrm{A}$ and root $\mathrm{B}$, was separately incubated in a little tube with a 5-ml volume filled with plant growth medium, and the remaining roots were kept out of the medium or cut off. After 1 or 2 days of additional incubation, the plants could be used for split-root experiments with bacteria or other additions such as Nod factors (dissolved in 1\% Chaps [Sigma, Zwijndrecht, The Netherlands], final concentration in the tubes maximally $0.01 \%$ Chaps) and plant growth factors. Simultaneous with these additions, unless otherwise stated, AVG (Sigma), final concentration of $0.2 \mathrm{mg} / \mathrm{liter}$, was routinely added to the tubes to prevent formation of the stress hormone ethylene.

\section{Preparation and quantification of Rhizobium Nod factors.}

Nod factors were extracted from overnight Rhizobium cultures in B medium containing the inducer naringenin $(1 \mu \mathrm{M})$. Extractions and purification of Nod factors were performed according to Spaink and colleagues (1990). The fractions containing Nod factors carrying C18:4 fatty acids, as produced by strain RBL5601, which is those with four or five glucosamin residues, were combined and called specific Nod factors (Spaink et al. 1990). Similar fractions containing the C18:1 fatty acids, produced by the nodE::Tn5 strain RBL5602, were combined and called nonspecific Nod factors. Both types of Nod factors, specific and nonspecific, carry a nodL-related $O$ acetyl group attached to C6 of the terminal sugar molecule at the nonreducing end of the chitin oligosaccharide moiety (Spaink et al. 1990). For quantification of the purified Nod factors, a molecular absorption coefficient (MAC) in $60 \%$ acetonitrile/ water was determined. For specific Nod factors, a MAC of 30,000 at 303-nm wavelength (H. P. Spaink, personal communication) was confirmed, and a MAC of 6,000 at 206-nm wavelength was determined for nonspecific Nod factors.

\section{Microscopic techniques.}

Infection of Vicia plants with Rhizobium bacteria was examined by using bacterial strains carrying a fusion of the reporter gene lacZ of Escherichia coli to the hemA gene promoter of $S$. meliloti (Leong et al. 1985). $\beta$-Galactosidase activity was as- sayed as described by Boivin and colleagues (1990) with 5bromo-4-chloro-3-indolyl- $\beta$-D-galactopyranoside (X-Gal) as a substrate. Roots were cleared with commercial bleach containing hypochlorite (4\% active chloride) (Truchet et al. 1989). Histochemical staining of starch was performed on cleared roots (Truchet et al. 1989) and root sections with a solution of $2 \% \mathrm{KI}$ and $0.1 \% \mathrm{I}_{2}$ in $\mathrm{H}_{2} \mathrm{O}$ (Vasse et al. 1990).

\section{Analytical procedures.}

$\mathrm{pH}$ measurements were performed in the tubes of root $\mathrm{A}$ or root B after withdrawal of the roots from the tube. To follow $\mathrm{pH}$ changes in time, each measurement was from a different tube, and for each time point or condition, a minimum of six tubes was measured. Means of numbers of nodules were also determined from a minimum of six plants. The bars in the graphs are error bars representing the standard deviation of the means.

\section{ACKNOWLEDGMENTS}

We gratefully acknowledge M. Harteveld for purification of the Nod factors, G. Lamers for help with the microscopy, and A. Wijfjes for providing us with strains and for discussions. We thank F. Temprano and coworkers for providing us with Vicia seeds and F. J. Ruiz-Sainz for discussions. P. Hock is acknowledged for drawing Figure 1 and for his assistance with the preparation of the figures. Photographs were made by A. 't Hooft, P. A. van Mulken, and R. M. Speksnijder.

\section{LITERATURE CITED}

Bauer, P., Ratet, P., Crespi, D., Schultze, M., and Kondorosi, A. 1996. Nod factors and cytokinins induce similar cortical cell division, amyloplast deposition and MsEnod12A expression patterns in alfalfa roots. Plant J. 10:91-105.

Beveridge, C. 2000. The ups and downs of signalling between root and shoot. New Phytol. 147:413-416.

Boivin, C., Camut, S., Malpica, C. A., Truchet, G., and Rosenberg, C. 1990. Rhizobium meliloti genes encoding catabolism of trigonelline are induced under symbiotic conditions. Plant Cell 2:1157-1170.

Boot, K. J. M., van Brussel, A. A. N., Tak, T., Spaink, H. P., and Kijne, J. W. 1999. Lipochitin oligosaccharides from Rhizobium leguminosarum bv. viciae reduce auxin transport capacity in Vicia sativa subsp. nigra roots. Mol. Plant-Microbe Interact. 12:839-844.

Caetano-Anolles, G., and Gresshoff, P. M. 1991. Plant genetic control of nodulation. Annu. Rev. Microbiol. 45:345-382.

Cooper, J. B., and Long, S. R. 1994. Morphogenetic rescue of Rhizobium meliloti mutants by trans-zeatin secretion. Plant Cell 6:215-225.

Delves, A. C., Mathews, A., Day, D. A., Carter, A. S., Carroll, B. J., and Gresshoff, P. M. 1986. Regulation of the soybean-Rhizobium nodule symbiosis by shoot and root factors. Plant Physiol. 82:588-590.

Delves, A. C., Higgins, A. V., and Gresshoff, P. M. 1987. Shoot control of supernodulation in a number of mutant soybeans, Glycine max (L.) Merr. Aust. J. Plant Physiol. 14:689-694.

Duc, G., and Messager, A. 1989. Mutagenesis of pea (Pisum sativum L.) and the isolation of mutants for nodulation and nitrogen fixation. Plant Sci. 60:207-213.

Francisco, P. B., Jr., and Harper, J. E. 1995. Translocatable leaf signal autoregulates soybean nodulation. Plant Sci. 107:167-176.

Hooykaas, P. J. J., Schnijdewindt, F. G. M., and Schilperoort, R. A. 1982. Identification of the Sym plasmid of Rhizobium leguminosarum strain 1001 and its transfer to and expression in other rhizobia and Agrobacterium tumefaciens. Plasmid 8:73-82.

Kosslak, R. M., and Bohlool, B. B. 1984. Suppression of nodule development of one side of a split-root system of soybeans caused by prior inoculation of the other side. Plant Physiol. 75:125-130.

Leong, S. A., Williams, P. H., and Ditta, G. S. 1985. Analysis of the 5' region of the gene for $\delta$-aminolaevulinic acid synthase of Rhizobium meliloti. Nucleic Acids Res. 13:5965-5976.

Libbenga, K. R., van Iren, F., Bogers, R. J., and Schraag-Lamers, M. F. 1973. The role of hormones and gradients in the initiation of cortex proliferation and nodule formation in Pisum sativum L. Planta 114:2939

Mathesius, U., Charon, C., Rolfe, B. G., Kondorosi, A., and Crespi, M. 2000. Temporal and spatial order of events during the induction of cortical cell divisions in white cover by Rhizobium leguminosarum bv. 
trifolii inoculation or localized cytokinin addition. Mol. Plant-Microbe Interact. 13:617-628.

Penmetsa, R. V., and Cook, D. R. 1997. A legume ethylene-insensitive mutant hyperinfected by its rhizobial symbiont. Science 275:527-530.

Pierce, M., and Bauer, W. D. 1983. A rapid regulatory response governing nodulation in soybean. Plant Physiol. 73:286-290.

Postma, J. G., Jacobsen, E., and Feenstra, W. J. 1988. Three pea mutants with an altered nodulation studied by genetic analysis and grafting. J. Plant Physiol. 132:424-430.

Priem, W. J. E., and Wijffelman, C. A. 1984. Selection of strains cured of the Rhizobium leguminosarum Sym plasmid pRL1JI by using small bacteriocin. FEMS (Fed. Eur. Microbiol. Soc.) Microbiol. Lett. 25: 247-251.

Sheng, C., and Harper, J. E. 1997. Shoot versus root signal involvement in nodulation and vegetative growth in wild type and hypernodulating soybean genotypes. Plant Physiol. 133:825-831.

Smit, G., Koster, C. C., Schripsema, J., Spaink, H. P., van Brussel, A. A. N., and Kijne, J. W. 1995. Uridine, a cell division factor in pea roots. Plant Mol. Biol. 26:869-873.

Spaink, H. P., Sheeley, D. M., van Brussel, A. A. N., Glushka, J., York, W. S., Tak, T., Geiger, O., Kennedy, E. P., Reinhold, V. N., and Lugtenberg, B. J. J. 1991. A novel highly unsaturated fatty acid moiety of lipo-oligosaccharide signals determines host specificity of Rhizobium. Nature (Lond.) 354:125-131.

Truchet, G., Camut, S., de Billy, F., Odorico, R., and Vasse, J. 1989. The Rhizobium-legume symbiosis: Two methods to discriminate between nodules and other root derived structures. Protoplasma 149:82-88.

van Brussel, A. A. N., Planqué, K., and Quispel, A. 1977. The wall of Rhizobium leguminosarum in bacteroid and free-living forms. J. Gen. Microbiol. 101:51-56.

van Brussel, A. A. N., Tak, T., Wetselaar, A., Pees, E., and Wijffelman, C. A. 1982. Small leguminosae as test plants for nodulation of Rhizobium leguminosarum and other rhizobia and agrobacteria harbouring a leguminosarum Sym-plasmid. Plant Sci. Lett. 27:317325 .

van Brussel, A. A. N., Zaat, S. A. J., Canter-Cremers, H. C. J., Wijffelman, C. A., Pees, E., Tak, T., and Lugtenberg, B. J. J. 1986. Role of plant root exudate and sym plasmid-localized nodulation genes in the synthesis by Rhizobium leguminosarum of Tsr factor which causes thick and short roots on common vetch. J. Bacteriol. 165:517-522. van Brussel, A. A. N., Recourt, K., Pees, E., Spaink, H. P., Tak, T. Wijffelman, C. A., Kijne, J. W., and Lugtenberg, B. J. J. 1990. A biovar-specific signal of Rhizobium leguminosarum bv. viciae induces increased nodulation gene-inducing activity in root exudate of Vicia sativa subsp. nigra. J. Bacteriol. 172:5394-5401.

van Brussel, A. A. N., Bakhuizen, R., van Spronsen, P. C., Spaink, H. P., Tak, T., Lugtenberg, B. J. J., and Kijne, J. W. 1992. Induction of preinfection thread structures in the leguminous host plant by mitogenic lipo-oligosaccharides of Rhizobium. Science 257:70-72.

van Workum, W. A. T., van Brussel, A. A. N., Tak, T., Wijffelman, C. A., and Kijne, J. W. 1995. Ethylene prevents nodulation of Vicia sativa ssp. nigra by exopolysaccharide-deficient mutants of Rhizobium leguminosarum bv. viciae. Mol. Plant-Microbe Interact. 8:278-285.

van Workum, W. A. T., Canter Cremers, H. J. C., Wijfjes, A. H. M., van der Kolk, C., Wijffelman, C. A., and Kijne, J. W. 1997. Cloning and characterization of four genes of $R$. leguminosarum bv. trifolii involved in exopolysaccharide production and nodulation. Mol. PlantMicrobe Interact. 10:290-301.

van Workum, W. A. T., van Slageren, S., van Brussel, A. A. N., and Kijne, J. W. 1998. Role of exopolysaccharides of Rhizobium leguminosarum bv. viciae as host plant-specific molecules required for infection thread formation during nodulation of Vicia sativa. Mol. Plant-Microbe Interact. 11:1233-1241.

Vasse, J., de Billy, F., Camut, S., and Truchet, G. 1990. Correlation between ultrastructural differentiation of bacteroids and nitrogen fixation in alfalfa nodules. J. Bacteriol. 172:4295-4306.

Vincent, J. M. 1970. Pages 75 and 7, respectively, in: IBP Handbook No. 15. Blackwell Scientific Publications, Oxford

Wijffelman, C. A., Pees, E., van Brussel, A. A. N., Okker, R., and Lugtenberg, B. J. J. 1985. Genetic and functional analysis of the nodulation region of Rhizobium leguminosarum Sym plasmid pRL1JI. Arch. Microbiol. 143:225-232.

Wopereis, W., Pajuelo, E., Dazzo, F. B., Jiang, G., Gresshoff, P. M., de Bruijn, F. J., Stougaard, J., and Szczyglowski, K. 2000. Short root mutant of Lotus japonicus with a dramatically altered symbiotic phenotype. Plant J. 23:97-114.

Zaat, S. A. J., van Brussel, A. A. N., Tak, T., Lugtenberg, B. J. J., and Kijne, J. W. 1989. The ethylene-inhibitor aminoethoxyvinylglycine restores normal nodulation by Rhizobium leguminosarum biovar. viciae on Vicia sativa subsp. nigra by suppressing the "thick and short roots" phenotype. Planta 177:141-150. 